Tropical Journal of Pharmaceutical Research April 2020; 19 (4): 817-821

ISSN: $1596-5996$ (print); 1596-9827 (electronic)

(C) Pharmacotherapy Group, Faculty of Pharmacy, University of Benin, Benin City, 300001 Nigeria.

\title{
Anti-endometriotic effect of Angelica sinensis (Oliv.) Diels extract in human endometriotic cells and rats
}

\author{
Qi-Xiang Xiong ${ }^{1}$, Xiao-Yun Ruan², Ai-Ping Deng ${ }^{2 *}$, Jue Liu², Qing Zhou² \\ ${ }^{1}$ Tongji Medical College Hospital, Huazhong University of Science and Technology, Wuhan 430030, ${ }^{2}$ Department of Pharmacy, \\ The Central Hospital of Wuhan, Tongji Medical College, Huazhong University of Science and Technology, Wuhan 430014, \\ China
}

*For correspondence: Email: ganlanxiang@126.com

Sent for review: 18 June 2019

Revised accepted: 28 January 2020

\begin{abstract}
Purpose: To study the anti-endometriotic effect of Angelica sinensis (Oliv.) Diels extract (ASDE) in human endometriotic cells and rats.

Method: Forty female rats were randomly divided into four groups (10 rats/group): control, endometriosis+danazol, endometriosis +high dose of ASDE and low dose of ASDE. The rats were orally administered either vehicle (200 $\mu$ L of PBS) alone or ASDE (140, 280 and $560 \mathrm{mg} / \mathrm{kg} /$ day) for 5 weeks. Danazol was used as the control drug. After induction of endometriosis for 4 weeks, the rats were sacrificed by cervical dislocation and the peritoneum and visceral organs examined visually to measure the number of endometriotic lesions. Serum levels of cancer antigen 125 (CA-125) and interleukin 13 (IL-13), interleukin 18 (IL-18) and tumor necrosis factor-alpha (TNF- $\alpha$ ) of peritoneal fluids of rats were measured using ELISA kits. Western blot assay was performed to measure the levels of matrix metalloproteinase-2 (MMP-2) and matrix metalloproteinase-9 (MMP-9) expressions after $24 h$ of treatment with $A S D E(30,60$, and $120 \mu \mathrm{g} / \mathrm{mL})$.

Results: ASDE-treated rats displayed reduced numbers of total endometriotic lesions when compared with vehicle-treated controls ( $p$ < 0.01). When the rats were treated with high dose of ASDE, serum CA125 level, as well as IL-18 and TNF- $\alpha$ levels in peritoneal fluids were significantly lower than that of the control group ( $p<0.01$ ); however, IL-13 level in peritoneal fluids was significantly higher than that of the control group $(p<0.01)$. ASDE treatment significantly suppressed the levels of MMP-2 and MMP-9 protein in $11 Z$ cell $(p<0.01)$.

Conclusion: The results reveal that ASDE exhibits significant anti-endometriotic effect by inhibiting inflammatory factors in rats. Thus, the plant extract can potentially be developed for the clinical management of endometriosis.
\end{abstract}

Keywords: Angelica sinensis, Endometriosis, Cancer antigen, Endometriotic lesions, Matrix metalloproteinase

This is an Open Access article that uses a fund-ing model which does not charge readers or their institutions for access and distributed under the terms of the Creative Commons Attribution License (http://creativecommons.org/licenses/by/4.0) and the Budapest Open Access Initiative (http://www.budapestopenaccessinitiative.org/read), which permit unrestricted use, distribution, and reproduction in any medium, provided the original work is properly credited.

Tropical Journal of Pharmaceutical Research is indexed by Science Citation Index (SciSearch), Scopus, International Pharmaceutical Abstract, Chemical Abstracts, Embase, Index Copernicus, EBSCO, African Index Medicus, JournalSeek, Journal Citation Reports/Science Edition, Directory of Open Access Journals (DOAJ), African Journal Online, Bioline International, Open-J-Gate and Pharmacy Abstracts

\section{INTRODUCTION}

Endometriosis is a common gynaecological disease that affects approximately 1 in 7 women and $30-50 \%$ of infertile women [1]. The symptoms of the disorder are dysmenorrhoea, chronic pelvic pain and infertility. Endometriosis is characterised by ectopic implantation and growth of endometrial tissue and local sterile inflammation of peritoneal cavity. Proliferation, 
adhesion, and migration of ectopic endometrial tissue are required to establish endometriotic lesions in the peritoneal cavity [2]. In addition, the expression of matrix metalloproteinase (MMP)-2 and MMP-9 have been shown to be higher in women with endometriosis than in healthy controls [3].

Endometriosis-associated inflammatory response, tissue repair and neo-vascularization are dependent on the peritoneal fluids macrophages and their secretary products/cytokines [4]. These cytokines may play major roles in regulating cell proliferation, activation, motility, adhesion, chemotaxis and morphogenesis in the pathogenesis of endometriosis [5]. Increased peritoneal fluid concentrations of cytokines that lead to the migration, proliferation, and activation of macrophages have been reported in patients with endometriosis.

The biomarkers such as cancer antigen 125 (CA125) and IL-13, IL-18 and TNF-alpha levels in the peritoneal fluids were related with endometriosis [6]. Although surgical and hormonal treatment are applied as the common interventions, the unpleasant side effects limited the use of these interventions [7]. Some traditional plant medicine were shown to be potential treatment for the disease [8].

Angelica sinensis (Oliv.) Diels has been used to treat endometriosis for many years and has achieved good curative action. In this study, the anti-endometriotic effect of ASDE was investigated in human endometriotic cells and rats.

\section{EXPERIMENTAL}

\section{Preparation of ASDE}

The medicinal herbs of Angelica sinensis (Oliv.) Diels weighing 5 kilogram were collected from Guilin City, Guangxi Province in China in October 2018. Taxonomic identification of the plants was performed by Prof Meng Wang of Wuhan University China. A voucher specimen (no. ASDE 20171008) was deposited in the herbarium of College of Pharmacy, Wuhan University, China for future reference.

One batch of Angelica sinensis (Oliv.) Diels was dried in an oven. ASDE was prepared by steeping the dried Angelica sinensis (Oliv.) Diels in hot water $\left(60^{\circ} \mathrm{C}\right)$ three times ( $1 \mathrm{~h}$ each time). The extract was dried first in an oven and then freeze-dried. The yield was $73.45 \%$.

\section{Animals and grouping}

Female Wistar rats weighing 200 - $220 \mathrm{~g}$ were obtained from Experimental Animal Center of Hubei Province, Hubei, China. The animals had free access to feed and water, and were allowed to acclimatize for at least one week before use. All animal experiments were approved by the Animal Care and Use Committee of Wuhan Center hospital (approval ref no. 20110508) and were carried out in compliance with the Animal Welfare Act and the $\mathrm{NIH}$ guidelines (NIH publication no. 80-23, revised 1996) [9]. Endometriosis was induced in rats using a previously established method with modifications [10]. The uterine horns of the donor mice were removed and put into a dish containing PBS. The endometrium-rich fragments $(1 \mathrm{~cm})$ from the middle-third of the uterine horn were finely and uniformly chopped.

The fragments ( $~ 20$ sections) suspended in PBS were injected into the peritoneal cavity of recipient mice with a micropipette to induce the formation of endometriosis-like lesions. Forty (40) rats with induced endometriosis were randomly divided into four groups (10 rats/group): control, Danazol $\circledast$, high dose ASDE and low dose ASDE. Ten normal rats were used as sham group. Rats were orally administered either vehicle (200 $\mu \mathrm{L}$ of PBS) alone or ASDE (140, 280 and $560 \mathrm{mg} / \mathrm{kg} /$ day) for 5 weeks. Danazol was used as the control drug. Danazol produces high androgen and low estrogen levels, which leads to the atrophy of endometriotic implants [11]. After induction of endometriosis for 4 weeks, the rats were sacrificed by cervical dislocation, and the peritoneum and visceral organs were examined visually to measure the number of endometriotic lesions $(1>\mathrm{mm})$.

\section{Enzyme linked immunosorbent assay}

The rats were sacrificed by carbon dioxide execution and the samples of peritoneal fluids and serum were taken. The peritoneal fluid samples were centrifuged at $12,000 \mathrm{rpm}$ for 10 $\min$ at $4{ }^{\circ} \mathrm{C}$. Then, the supernatants were collected, aliquoted, and stored frozen at $-80{ }^{\circ} \mathrm{C}$ until used for further evaluation. Serum CA-125 levels, and the levels of IL-13, IL-18 and TNF- $\alpha$ of the peritoneal fluids were determined using ELISA as directed by the manufacturer (RUIQI Bio Co. Ltd, Shanghai, China).

\section{Cell culture and cell viability}

Immortalised human endometriotic cells $11 Z$ cell were kindly provided by Nanjing Ke Biological Technology Co., Ltd., Nanjing, China. The 
endometriotic cells were cultured in DMEM/F12 medium supplemented with $100 \mathrm{U} / \mathrm{mL}$ penicillin $\mathrm{G}, 100 \mathrm{~g} / \mathrm{mL}$ streptomycin, and $10 \%$ FBS. Met5A cells (human mesothelial cells) is originally from the American Type Culture Collection (Manass-as, VA, USA). Met5A cells were cultured in Medium 199 medium supplemented with $100 \mathrm{U} / \mathrm{mL}$ penicillin G, 100 $\mathrm{g} / \mathrm{mL}$ streptomycin, $10 \%$ FBS and $400 \mathrm{nM}$ hydrocortisone.

The cells were maintained in a humidified atmosphere of $5 \% \mathrm{CO}_{2}-95 \%$ air at $37{ }^{\circ} \mathrm{C}$. Cell viability was estimated using the MTT (3-(4,5dimethylthiazol-2-yl)-2,5-dipheyl tetrazolium bromide; Sigma-Aldrich) assay. Cells were seeded in 96-well plates at a density of $5 \times 10^{3}$ cells per well and incubated for $24 \mathrm{~h}$. To study the effect of ASDE, the cells were treated with ASDE $(30,60$ and $120 \mathrm{ug} / \mathrm{mL})$ for $48 \mathrm{~h}$. MTT solution was added into the medium and the cells were incubated at $37^{\circ} \mathrm{C}$ for $4 \mathrm{~h}$. The MTTcontaining medium was removed and the cells were solubilized in DMSO $(100 \mu \mathrm{L})$ for $30 \mathrm{~min}$.

The absorbance was determined at $490 \mathrm{~nm}$ using a microplate spectrophotometer (Fisher Scientific Ltd., Ottawa, ON, Canada).

\section{Statistical analysis}

Data are expressed as mean \pm SD. Statistical comparison between two groups was made using Student's $t$-test. For comparing more than two groups, one-way analysis of variance (ANOVA) was used followed by Tukey test with statistical significance set at $p<0.05$.

\section{RESULTS}

\section{ASDE inhibited the formation of endometriosis-like lesions in rats}

As shown in Table 1, compared with vehicletreated controls, ASDE-treated rats had reduced number of total endometriotic lesions $(p<0.01)$. Thus, ASDE inhibited the formation of endometriosis-like lesions in the rats.
Table 1: Effect of ASDE on the formation of endometriosis-like lesions in rats $(n=10)$

\begin{tabular}{lc}
\hline Group & No. of lesions/mouse \\
\hline & \\
\hline Normal & $9.1 \pm 1.2^{* *}$ \\
Control & $24.3 \pm 1.1$ \\
Danazol & $18.2 \pm 1.4^{*}$ \\
ASDE-H & $10.4 \pm 1.1^{* *}$ \\
ASDE-M & $13.8 \pm 1.8^{*}$ \\
ASDE-L & $15.2 \pm 1.2^{*}$ \\
\hline${ }^{*} P<0.05,{ }^{* *} p<0.01$ compared with control group
\end{tabular}

\section{Effect of ASDE on serum biomarkers in rats}

As shown in Table 2, the serum CA-125 level, and the levels IL-18 and TNF- $\alpha$ of peritoneal fluids in control group rats were higher than those of sham group $(p<0.01)$. The serum CA$125, \mathrm{IL}-18$ and TNF- $\alpha$ levels of peritoneal fluids of high dose of ASDE decreased significantly than that of the control group $(p<0.01)$. The IL13 level of peritoneal fluids in control group was significantly lower than that of sham group $(p<$ 0.01). After treatment with high dose of ASDE, the IL-13 level of peritoneal fluids was significantly higher than that of the control group $(p<0.01)$.

\section{DISCUSSION}

Endometriosis is usually associated with inflammation of the pelvic area and peritoneum. This hallmark has led to searching for inflammatory markers in the circulation which could potentially predict the presence of endometriosis, and the possibility of a clinically silent systemic inflammatory state in women with endometriosis. These results are largely similar with minimal differences at a level which precludes their use as diagnostic biomarkers for endometriosis. This may explain why there has been no unequivocal consensus of the circulating cytokine levels in endometriosis [13].

In this study, CA125, IL-13, IL-18 and TNF- $\alpha$ levels were chosen to reflect the effect of ASDE on the model rats established with endometriosis.

Table 2: Effect of ASDE on biochemical profile of rats

\begin{tabular}{lcccc}
\hline Group & CA-125 (U/mL) & IL-13 (pg/mL) & $\begin{array}{c}\text { IL-18 } \\
(\mathrm{pg} / \mathrm{mL})\end{array}$ & $\begin{array}{c}\text { TNF- } \alpha \\
(\mathrm{pg} / \mathrm{mL})\end{array}$ \\
\hline Normal & $4.6 \pm 0.5^{* *}$ & $8.2 \pm 1.2^{* *}$ & $124.3 \pm 9.4^{* *}$ & $225.1 \pm 16.3^{* *}$ \\
Control & $14.2 \pm 1.2$ & $2.1 \pm 0.8$ & $312.4 \pm 18.2$ & $846.4 \pm 11.3^{* *}$ \\
Danazol & $6.4 \pm 1.5^{* *}$ & $6.1 \pm 1.1^{* *}$ & $120.1 \pm 8.4^{* *}$ & $252.2 \pm 13.5^{* *}$ \\
ASDE-H & $6.7 \pm 1.3^{* *}$ & $7.8 \pm 0.7^{* *}$ & $113.1 \pm 7.2^{* *}$ & $234.1 \pm 11.4^{* *}$ \\
ASDE-M & $8.56 \pm 2.4^{*}$ & $6.4 \pm 1.2^{*}$ & $138.27 \pm 9.5^{*}$ & $257.9 \pm 12.3^{*}$ \\
ASDE-L & $10.2 \pm 2.2^{*}$ & $5.2 \pm 0.8^{*}$ & $148.3 \pm 10.2$ & $299.3 \pm 15.4^{*}$ \\
\hline
\end{tabular}

${ }^{*} P<0.05,{ }^{* *} p<0.01$ compared with control group 
Serum CA-125 measurement is now a consolidated method for diagnosing endometriosis, and the serum CA-125 values were found significantly elevated in patients with ovarian and mixed endometriosis lesions [14]. The level of IL-18 in peritoneal fluids was markedly higher in women with peritoneal, minimal-to mild-stage endometriosis than in controls [15]. The level of TNF- $\alpha$ in peritoneal fluids was demonstrated as a biomarker to discriminate between patients with and without endometriosis [16]. It was found that ASDE markedly decreased the serum levels of CA-125 as well as the levels of IL-18 and TNF- $\alpha$ in the peritoneal fluids, and significantly increased the levels of IL-13 in the peritoneal fluids.

Matrix metalloproteinase (MMPs), a family of zinc-dependent endopeptidases, are known to regulate the migration, invasion, and proliferation of various cell types [17]. In recent years, accumulating data suggest that MMPs are associated with the establishment and progression of endometriosis. For example, MMP levels were shown to be enhanced in ectopic endometriotic tissues [18]. It was. reported that MMP levels in endometrial tissue are related to the ability of the tissue to progress into ectopic endometriotic lesions in a mouse endometriosis model [19]. Among the various MMPs, gelatinases MMP-2 and MMP-9, which degrade the principal component of basement membranes, (collagen IV), have been intensively investigated in the context of endometriosis.

MMP-2 and MMP-9 are elevated in the peritoneal fluid of patients with endometriosis compared to healthy people [20]. Similarly, induction of endometriosis enhanced the levels of MMP-2 and MMP-9 in peritoneal fluid and cells in an in vivo study using BALB/c mice [21]. In addition, human endometriotic tissues were shown to have higher levels and activities of MMP-2 and MMP-9 [22]. In this study, it was showed that ASDE significantly suppressed the mRNA and protein levels of MMP-2 and MMP-9 in $11 \mathrm{Z}$ cell, suggesting that ASDE modulated MMP-2/-9 expression at the transcriptional level. Downregulation of MMP-2 and MMP-9 by ASDE may involve the inhibition of ASDE-induced migration in human endometriotic cells, considering that MMPs have been implicated in the endometriotic cell migration.

\section{CONCLUSION}

The findings of this study reveal that ASDE shows significant anti-endometriotic effect by inhibiting inflammatory factors Thus, it can potentially be developed as a medicinal agent for the management of endometriosis.

\section{DECLARATIONS}

\section{Conflict of interest}

No conflict of interest is associated with this work.

\section{Contribution of authors}

We declare that this work was done by the authors named in this article and all liabilities pertaining to claims relating to the content of this article will be borne by the authors. Qi-Xiang Xiong and Xiao-Yun Ruan contributed to this work equallly and are co-first authors of this paper.

\section{Open Access}

This is an Open Access article that uses a funding model which does not charge readers or their institutions for access and distributed under the terms of the Creative Commons Attribution License (http://creativecommons.org/licenses/by/ 4.0) and the Budapest Open Access Initiative (http://www.budapestopenaccessinitiative.org/rea d), which permit unrestricted use, distribution, and reproduction in any medium, provided the original work is properly credited.

\section{REFERENCES}

1. Bulun SE. Endometriosis. N Engl J Med 2009; 360: 268279.

2. Van Langendonckt A, Casanas-Roux F, Donnez J. Oxidative stress and peritoneal endometriosis. Fertil Steril 2002; 77: 861-870.

3. Bedaiwy MA, Falcone $T$, Sharma RK, Goldberg JM, Attaran M, Nelson DR. Prediction of endometriosis with serum and peritoneal fluid markers: a prospective controlled trial. Hum Reprod 2002; 17: 426-431.

4. Che XH, Park EJ, Zhao YZ, Kim WH. Tanshinone II A induces apoptosis and $S$ phase cell cycle arrest in activated rat hepatic stellate cells. Basic Clin Pharmacol Toxicol 2010; 106: 30-37.

5. Chen X, Zhou ZW, Xue CC, Li XX. Role of P-glycoprotein in restricting the brain penetration of tanshinone IIA, a major active constituent from the root of Salvia miltiorrhiza Bunge, across the blood-brain barrier. Xenobiotica 2007; 37: 635- 678.

6. Fassbender A, Overbergh L, Verdrengh E, Kyama CM. How can macroscopically normal peritoneum contribute to the pathogenesis of endometriosis? Fertil Steri 2011; 96: 697-699. 
7. Flower A, Lewith GT, Little P. Seeking an oracle: using the Delphi process to develop practice guidelines for the treatment of endometriosis with Chinese herbal medicine. J Altern Complement Med 2007; 13: 969-976.

8. Giudice LC, Kao LC. Endometriosis. Lancet 2004; 364: 1789-1799.

9. European Commission [homepage on the internet]. Directive 2010/63/EU on the protection of animals used for scientific purposes [cited 2013 Jan 16]. Available from: http://ec.europa.eu/environment/chemicals/lab_ani mals/legislation_en.htm.

10. Chen Q, Zhou W, Pu D, Li Z. The inhibitory effect of 15-rIxa4 on experimental endometriosis. Eur J Obstet Gynecol Reprod Biol 2009; 145: 200-204.

11. Garai J, Molnar V, Varga T. Endometriosis: Harmful survival of an ectopic tissue. Front Biosci 2006; 11: 595619.

12. Zeitvogel A, Baumann $R$, Starzinski-Powitz $A$. Identification of an invasive, $n$-cadherin-expressing epithelial cell type in endometriosis using a new cell culture model. Am J Pathol 2001; 159: 1839-1852.

13. Li W, Li ZW, Han JP, Li XX, Gao J. Determination and pharmacokinetics of danshensu in rat plasma after oral administration of danshen extract using liquid chromatography/tandem mass spectrometry. Eur J Drug Metab Pharmacokinet 2008; 33: 9-16.

14. Liu H, Lang JH. Is abnormal eutopic endometrium the cause of endometriosis? The role of eutopic endometrium in pathogenesis of endometriosis. Med Sci Monit 2011; 17: 92-99.
15. Liu $T$, Jin $H$, Sun $Q R, X u J H$. The neuroprotective effects of tanshinone IIA on beta-amyloid-induced toxicity in rat cortical neurons. Neuropharmacol 2010; 59: 595-604.

16. Matkowski A, Zielinska S, Oszmianski J. Antioxidant activity of extracts from leaves and roots of Salvia miltiorrhiza Bunge, S. przewalskii Maxim., and $S$. verticillata L. Bioresour Technol 2008; 99: 7892-7896.

17. Sternlicht $M D$, Werb Z. How matrix metalloproteinases regulate cell behavior. Annu Rev Cell Dev Biol 2001; 17: 463-516.

18. Zhou HE, Nothnick WB. The relevancy of the matrix metalloproteinase system to the pathophysiology of endometriosis. Front Biosci 2005;10: 569-575.

19. Styer AK, ullivan BT, Puder M, Arsenault D. Ablation of leptin signaling disrupts the establishment, development, and maintenance of endometriosis-like lesions in a murine model. Endocrinol 2008; 149: 506514.

20. Chung HW, Lee JY, Moon HS. Matrix metalloproteinase2, membranous type 1 matrix metalloproteinase, and tissue inhibitor of metalloproteinase-2 expression in ectopic and eutopic endometrium. Fertil Steril 2002; 78 : 787-795.

21. Huang HF, Hong LH, Tan Y. Matrix metalloproteinase 2 is associated with changes in steroid hormones in the sera and peritoneal fluid of patients with endometriosis. Fertil Steril 2004; 81: 1235-1239.

22. Zong WX, Edelstein LC, Chen C. The prosurvival bcl-2 homolog bfl-1/a1 is a direct transcriptional target of nfkappab that blocks tnfalpha-induced apoptosis. Genes Dev 1999; 13: 382-387. 